\title{
Code-switching in the media: Identity negotiations in a Gujarati diaspora radio program
}

\author{
Zipp, Lena
}

\begin{abstract}
This article aims to explore the construction of post-diasporic, hybrid local identities in communicative practices of the younger British Gujarati community. It focuses on the host of a popular BBC Asian Network radio show as a prominent voice of this community, who simultaneously embodies and creates linguistic community values through the use of Gujarati-English code-switching. In doing so, it highlights the role of the media in shaping a space for the linguistic negotiation of local and transnational influences. On a methodological level, the article argues for the combination of data from different domains in the context of transnational identity negotiations, such as linguistic behavior, narrative language biographies, private and public meta-linguistic commentary, indications of language status and attitudes towards alternating language use.
\end{abstract}

DOI: https://doi.org/10.1515/ijsl-2017-0020

Posted at the Zurich Open Repository and Archive, University of Zurich ZORA URL: https://doi.org/10.5167/uzh-143552

Journal Article

Published Version

Originally published at:

Zipp, Lena (2017). Code-switching in the media: Identity negotiations in a Gujarati diaspora radio program. International Journal of the Sociology of Language, 247:33-48.

DOI: https://doi.org/10.1515/ijsl-2017-0020 


\title{
Lena Zipp* \\ Code-switching in the media: Identity negotiations in a Gujarati diaspora radio program
}

DOI 10.1515/ijsl-2017-0020

\begin{abstract}
This article aims to explore the construction of post-diasporic, hybrid local identities in communicative practices of the younger British Gujarati community. It focuses on the host of a popular BBC Asian Network radio show as a prominent voice of this community, who simultaneously embodies and creates linguistic community values through the use of Gujarati-English code-switching. In doing so, it highlights the role of the media in shaping a space for the linguistic negotiation of local and transnational influences. On a methodological level, the article argues for the combination of data from different domains in the context of transnational identity negotiations, such as linguistic behavior, narrative language biographies, private and public meta-linguistic commentary, indications of language status and attitudes towards alternating language use.
\end{abstract}

Keywords: code-switching, identity construction, meta-linguistic commentary, minority language radio, language attitudes

\section{Introduction}

The current article is embedded in a special issue on the social and linguistic corollaries of globalisation (e.g. Vertovec 2007; Blommaert and Rampton 2011) in Central and South Asia. It looks at communicative practices that are part of the UK's multilingual landscape, focusing on the local British substantiation of the transnational Gujarati community. In particular, the article considers, in an exemplary way, speech and interview data from Alpa Pandya, the host of a minority language radio show on the BBC Asian Network. It argues that radio, like all mass media communication, is operative in taking up in-group communicative practices, enforcing them, and providing a platform for the cultural validation of a localized sense of ethnic identity. As has been noted before,

*Corresponding author: Lena Zipp, University of Zurich, Zürich, Switzerland, E-mail: lena.zipp@es.uzh.ch 
[a]ll media language [...] creates the relationship between communicator and audience, rather than responding to an existing relationship. This holds supremely for radio, where announcers rely solely on their speech to project whatever relationship they have with the audience. Their style draws its effect from the norms of who such a style is addressed to in face-to-face interaction. They use style as an expressive instrument, a declaration of identity, saying to the audience 'you and I are ingroup'.

(Bell 1984: 192)

Alpa Pandya can therefore be seen as a highly influential member of the British Gujarati community. On the one hand, she draws on the norms that are present in her community of practice for the use of code-switching between English and Gujarati. On the other hand, she plays an important part in the "local dynamics of socio-cultural organisation" in enabling communal participation (Coupland 2010: 102) and shaping linguistic practices that are emblematic of the merging of local and transnational influences.

Previous social and linguistic descriptions of the Gujarati diaspora in the UK typically capture the tension of diasporic and local values. Part of one of the world's great diasporic movements, the history of Gujarati migration starts with and revolves around the transnational flow of successful merchants and businesspeople. One of the most prominent transnational Indian communities around the world today (Sahoo 2006), the Gujarati diaspora was predominantly formed through increased migration patterns around the turn of the twentieth century, away from Gujarat on the North-Western coast of the Indian subcontinent. This movement led Gujarati migrants first to East Africa and the Middle East, and then to Europe and North America (Sahoo 2006: 91-92). The sizeable Gujarati community in the UK comprises a large percentage of secondary migrants from East African countries such as Kenya, Tanzania and Uganda, from the latter particularly after forceful expulsion in the 1970s (Mattausch 2007). Previous sociological studies thus mainly trace the Gujaratis' migratory movements throughout history (e.g. Ramji 2006a; 2006b; Mattausch 2007), describe their global diasporic networks (e.g. Poros 2011), and explore their relations with the British host community (e.g. Mukadam and Mawani 2007). Most of these studies highlight the socioeconomic achievements of the Gujarati diaspora explicitly: "[T]he African emigrants, refugees, the British-born generations and those arriving directly from India have in a short time occupied a huge diversity of largely middle-class or self-employed positions in modern Britain along with a wide spread of workingclass jobs" (Mattausch 2007: 151). For the so-called twice migrants, the African South Asians, previous research has emphasized that a combination of reasons contributed to their fast socio-economic progress, such as the fact that the primary diaspora situation in East Africa had already resulted in a pre-selection of successful entrepreneurs, with the failed ones having returned to India before the 
secondary migration wave in the 1970s (Oonk 2006). Moreover, secondary migrants arriving in Britain from African countries "were better placed to succeed in Britain, having often arrived as intact families with business experience, with no cultural proscription against their women working, and with variable but far better educational levels" (Mattausch 2007: 154). In consequence, it was argued that because of, among other reasons, "their previous social position in East Africa, [...] the East African Asians in Britain would be far less encapsulated within their culture and community than their sub-continental counterparts" (Robinson 1993: 236, quoted in; Mattausch 2007: 153).

From a linguistic point of view, previous studies of British Gujarati speech paint a complex sociolinguistic picture that resonates with the above description of social conditions. While typical interference phenomena of the heritage language on the pronunciation of English are observed in first-generation speakers (Evans et al. 2007; Rathore 2013), ${ }^{1}$ second-generation Gujaratis in both previous studies adopt educated British accents rather than local non-standard ones, "most likely determined by their middle-class background, possibly in conjunction with other factors such as their affiliation with a British-Asian identity and positive orientation towards the host community" (Rathore 2013: 240). In Evans et al.'s (2007) study of Wembley Gujaratis, it was noted in particular that young second-generation Gujarati immigrants do not adopt the emerging local multiethnolect, Multicultural London English (Cheshire et al. 2011), to the same extent as speakers from other ethnic communities. The authors argue that this is due to their subjects' social mobility: "[I]nformal interviews with subjects suggested that they felt it was important to use a standard rather than an 'ethnic' accent in order to be accepted in their university community or workplace" (Evans et al. 2007: 1744). However, recent research in this community has devoted very little attention to the concept of hybrid orientation on a linguistic level, as could be achieved by looking at superdiverse, i.e. multilingual or hybrid, speech, and practices of language mixing in this particular community. ${ }^{2}$ The present article thus hones in on code-switching in language use and the linguistic

1 Note that first generation twice migrants in Leicester were shown to maintain linguistic continuity to subcontinental Indian English without apparent East African English influences. This is traced back to ethnic division in colonial East Africa, the steady influx of new migrants and import of teachers from the subcontinent, as well as the maintenance of strong ties to the original homeland (Rathore 2013: 231-234). See e.g. Alam and Stuart-Smith (2011), Sharma (2011), Sharma and Rampton (2015), and Sharma and Sankaran (2011) for studies of dialectal influences of other first languages from the Asian subcontinent on English varieties spoken by first- and second-generation migrants in the UK.

2 In this context, superdiverse is taken to refer to the actual phenomenon of code-switching, drawing on Vertovec's (2007) multi-dimensional definition of super-diversity in Britain. This 
self-construction of a Gujarati radio show host, selected by virtue of her status as an influential member of the British Gujarati community. It also discusses the role of the $\mathrm{BBC}$ as an institutional space that allows for the development and consolidation of communicative practices that are indicative of a postdiasporic, "hyphenated" Brit-Gujarati identity. In addressing these issues, I aim to achieve a more complete picture of localized discourses by including both language use data and meta-linguistic commentary from narrative interview data. This is in line with Blommaert and Rampton (2011: 11), who state that "a distinct view of ideology emerges" only in the combined ethnographic observation of explicitly articulated statements and "implicit behavioural reflexes operating in discourse practices (turning these into ideologically saturated praxis)".3

\section{Theorizing diaspora and identity in the context of British South Asians}

In the past decades, studies of diasporic communities around the world have provided new perspectives on migration, transnationalism, and identity, leading to a proliferation of current scholarship around the buzzword diaspora. The term, albeit being used for a variety of scenarios in a multitude of disciplines, rests on the following three core criteria: dispersion in space, orientation to a "homeland", and boundary-maintenance (Brubaker 2005: 5). It thus describes a specific kind of transnational group with an enduring presence abroad in two or more territories, and "some kind of exchange - social, economic, political or cultural - between or among the spatially separated populations comprising the diaspora" (Van Hear 1998: 6). ${ }^{5}$ When trying to contextualize and substantiate

stands in contrast to the paradigmatic approach to superdiversity postulated by e.g. Blommaert (2015: 83), a theoretically and methodologically explorative perspective that sees "complexity, hybridity, 'impurity' and other features of 'abnormal' sociolinguistic objects as 'normal'”.

3 At this point I have to acknowledge the limited scope of my data, which does not allow for researching the implications of outsider membership in the in-group (i.e., non-Gujarati listeners), or the nature and significance of in-group language practices and the interactions of that in-group with (cultural and generational) outsiders.

4 Some definitions also include "a myth of returning to one's homeland", "a sense of empathy and solidarity with similar groups elsewhere in the world and/or with events and groups in the homeland" (Oonk 2007: 14), and "alienation from the host nation" (Oonk 2007: 16).

5 See e.g. Brettell (2006) for a review of literature concerned with the distinction of diaspora and transnationalism. 
specific diaspora settings, however, it becomes clear that the concept reaches its limitations, with too narrow a focus on concrete factors such as the trajectories of peoples' movements, permanency of residence or sustained links to the homeland. A number of transnational Asian communities for example do not fit the criteria, which raises questions about the general applicability of the concept for sociological academic discourse (also see Oonk 2007). Moreover, a research bias appears to affect the triadic relationship between collectively selfidentified diasporic groups, their host countries, and countries of origin, as "studies on diasporas have tended to focus on origins over points of settlement in constructing identities and solidarities” (Ramji 2006a: 705).

In view of the shortcomings of the traditional definition, diaspora shall be understood here along the lines of Vertovec's (1999) description of transnationalism as type of consciousness, consisting of a collective awareness of multiple attachments, or of belonging simultaneously "here and there". Brubaker (2005: 13) similarly proposes that diaspora is preferably thought of as a de-substantialized concept, "by treating it as a category of practice, project, claim and stance, rather than as a bounded group". This is imperative for an investigation of younger British Asians, ${ }^{6}$ for whom "diasporas denote a social condition rather than a descriptive term, enabling one to unravel the nexus between the relative significance of place(s) of 'origin' and place(s) of settlement and to comprehend how the identities of second and third generation British Asians are subject to both" (Ramji 2006a: 705). For Gujarati Brits in particular, Mukadam and Mawani (2007: 209) claim that little or no connection to the homeland results in a reconstruction of "what it means to be British", particularly in the second, "post-diasporic" generation.

Finally, a third interpretation of diaspora will be drawn upon in the following. Vertovec's (1999: 451) understanding of transnationalism as mode of cultural reproduction resonates most with the data of the current study, as it describes processes and outcomes of cultural blending:

The production of hybrid cultural phenomena manifesting 'new ethnicities' (Hall 1991) is especially to be found among transnational youth whose primary socialisation has taken place with the cross-currents of differing cultural fields. Among such young people, facets of culture and identity are often self-consciously selected, syncretized and elaborated from more than one heritage.

(Vertovec 1999: 451)

6 In the context of this study, I am using younger to refer to second- and third-generation British Asians (as well as child generation community members if they were born abroad but migrated to the UK before the formative childhood and youth years, such as Alpa herself). 
This notion of blending facets of culture and identity from multiple heritage backgrounds can be transferred to the process of blending discursive practices, or general language use. While language maintenance in the diaspora is recognized as one of the most important pathways of transnational identity construction, post-modern society has long seen the deconstruction of the ideology of national languages. Instead, there is a multitude of different "styles, registers and genres" (Blommaert and Rampton 2011: 4) that are indicative of situated communicative practices, and linguistic repertoires for speakers to choose from in the construction and projection of their respective identity (Sharma 2011; 2012). It is the choice made within the linguistic repertoires of diasporic speakers then that has the potential to index most clearly a new, "in-between position" in the dynamic tension of the transnational and the local. The interplay of these two symbolic spaces becomes evident in the use of the different languages at the disposal of the transnational speaker: the heritage language(s) and the local language(s) (to whichever degree of proficiency or level of near-native pronunciation). In the words of Bhatt (2008: 181), "[t]he linguistic indexing of this liminal space, of new identity-position, is signaled through discoursal hybridity in texts and interactions: Code-switching is one exponent of that hybridity". The author thus sees linguistic hybridity as an imagined third space that offers those who see themselves as in-between "a mechanism to negotiate and navigate between a global identity and local practices” (Bhatt 2008: 182).

The investigation of code-switching (and code-mixing) in bilingual communities around the globe has a long tradition in sociolinguistic scholarship (e.g. Gumperz 1982; Poplack 1980; 1988; Myers-Scotton 1993; Auer 1999; 2002; Gardner-Chloros et al. 2000; Muysken 2000). ${ }^{7}$ Deliberately disregarding their specific analytic agendas for the time being, it can be said that all of these previous studies touch on three very general ideas: (1) that there is a continuum of forms and functions, ranging from discursive code-switching to fused lects; (2) that motivations for code-switching differ vastly, and that the speakers' awareness of switching can vary considerably in the process; and that (3) code-switching can but does not necessarily have to be used in identity work. When working with code-switching and other "messy" linguistic data, Blommaert (2015: 84) recommends to adopt a "perspective that enables us not just to analyze the messy contemporary stuff, but also to re-analyze and reinterpret more conventional and older data, now questioning the fundamental assumptions (almost inevitably language-ideological in character) previously used in analysis". I propose that actual communicative practices under observation cannot be evaluated without contextualizing them with respect to the

7 Code-switching in British Asian communities was observed by e.g. Gardner-Chloros et al. (2000), Lawson and Sachdev (2004), and Mukadam and Mawani (2007: 205). 
individual speaker's attitudes and linguistic identity construction, meta-linguistic commentary, the way in which media policies and constraints influence their realization, and their reception by the diasporic community that constitutes the radio audience. These distinct but intersecting facets of the communicative practice of code-switching range from the private to the public domain, intersecting various fields of power, ideology and symbolic space.

\section{The study: the BBC Asian network Gujarati radio program}

The data for this study come from archived broadcasts of a minority language radio program on the $B B C$ Asian Network as well as from an interview that I conducted with the radio presenter in September 2013. It thus seeks to explore and combine her personal linguistic identity construction with her mediated language use as an influential local voice of a transnational community.

The BBC Asian Network was established around the year 2000 as a national service. Its history dates back to its late 1970s origins as a regional radio station in Leicester, which makes it a typical example of the community radio movement of the time that later benefitted from increased government and economic support for linguistic minority broadcasting (Browne and Uribe-Jongbloed 2013: 3-5; Cormack 2005). In 2006, the BBC further increased funding, to make its budget the biggest of the BBC's then five digital radio stations, "in a bid to make British Asian interests a mainstream part of the corporation's output” (Day 2006). Its service remit on the radio website clearly emphasizes the local ties between the various targeted ethnic communities and their British connection, pointing to the station's commitment to "provide speech and music output appealing to the British Asian communities" but also "to anyone with an interest in British Asian issues, music and culture" (BBC Asian Network). By virtue of this remit (and in spite of their online, i.e. transnational availability), the diverse minority language programs produced by the $\mathrm{BBC}$ are thus to be considered "ethnic" rather than diaspora or transnational media. Ethnic programs "largely produce local shows focusing on minorities within a country of settlement" (Karim 2003: 11). In order to do so the network commits itself to broadcasting primarily in English, but also in heritage languages, as the controller of the BBC Asian Network stated in 2010: "We also provide a range of South Asian language programs that cater for our audience's hunger to explore their linguistic roots" (Andy Parfitt, quoted on BBC Asian Network).

For the British Gujarati community, this opportunity was realized with the addition of the highly popular Sunday evening late program Alpa Pandya to the 
network's portfolio in December 2012 (Alpa Pandya show). The program host lends her voice to the show in the true sense of the word, adopting a very personal style of code-switching between Gujarati and English that has proven to be highly successful with her listeners (as indicated by poll results and listener figures collected by the BBC, personal communication with Alpa Pandya). ${ }^{8}$ As the daughter of economically successful entrepreneurs from Tanzania, East Africa, who came to the UK when she was less than one year old, her personal ethnic identity construction is closely linked to her journey towards becoming the host of a Gujarati radio show. Albeit a story of success, this journey nevertheless appears to be emblematic of some of the typical identity negotiations undertaken by younger-generation diasporic heritage language speakers (see Example 1).

(1) Also, I think for me, being proud to be a Gujarati is the fact that I'm actually a presenter on the BBC Asian network, presenting a Brit-Gujarati show. Now, personally, in terms of language, Gujarati, yes, in my household we speak Gujarati, but when I was young I was very shy to speak our language, I used to always speak in English to my parents. Shy because I never was confident in speaking the language, so my mum and dad used to speak to me in Gujarati and I used to answer back in English, and there was times when my parents used to say to me 'why don't you speak to us in Gujarati at home?' and I used to say 'because I don't think I can speak it well'. [...] When I was young, in my teens, [...] I was forcefully sent to Gujarati school, which I absolutely hated. Hated because I just, I wasn’t interested in going. [...] But it's funny how your life pans out, that somebody who [...] wasn't comfortable speaking the language initially, was forced to go to Gujarati school, dropped out half-way through as well, and then ended up later on in her life to present a Gujarati show. (Pandya 2013, interview)

As the narrative in Example (1) depicts, Alpa considers her linguistic biography as erratic. However, research on the "process of maintenance of ethnic identity" (Isajiw 1975: 132, quoted in; Mukadam and Mawani 2007: 203) has traced this oscillation pattern as commonly following three stages: The pattern of "transplantation" of the old culture (for the first generation), the rebellion pattern (often exhibited by the second generation), and the returning or rediscovery pattern. "The second generation, having been born and/or brought up in the dominant society, can move through all three patterns, in any direction at any given time"

8 This personal style is seen as independent of whether Alpa engages in the construction of a linguistic persona on the radio through the repeated use of stylized language (Coupland 2001). 
(Mukadam and Mawani 2007: 204). For Alpa, the returning or rediscovery pattern was originally initiated in the family domain, although the impetus was given in connection with her career as a radio presenter (see Example 2).

(2) [B]eing a radio presenter, I've been in the industry for [...] 19 years in radio, and all the shows that I've presented have all always been in English, but when I was approached by BBC Asian network to present a Gujarati show targeted to the younger audience, initially I had said no. I rejected doing the show, simply because I wasn't confident in speaking the language. And it was then where the support of my parents came in, especially my mum who said to me 'what have you got to lose? Speak the language, you know, [...] it's not the pure Gujarati that you have to speak, you got to speak the language how you youngsters speak it, with a mixture of English, a mixture of Gujarati, and you know, you'll be fine'. So I listened to her and [...] I took on the show, and am now [...] nine months into the show, started in December 2012, and it's become a huge success.

(Pandya 2013, interview)

Her mother's reported awareness of the second generation's linguistic negotiation of local versus transnational influences in the language how you youngsters speak it, and her advice to disregard the pure Gujarati, can be taken to indicate not only that Gujarati-English code-switching is a widespread phenomenon, but also that it appears to be accepted within the Gujarati community. In the same vein, Alpa's own evaluation of the reception of her show suggests that she fully endorses the choice of a mixed code.

In the end, while judging the actual reception of the show within the community from narrative and reported statements has to remain tentative, the data can also be used to discover salient themes in the context of this particular sociolinguistic situation. For example, two aspects that surface as being linked to Gujarati-English code-switching in the media are that it is the preferred code of younger community members (Example 3), and that it is used with the aim of facilitating understanding both within the Gujarati and the host community (Example 4).

(3) I think when the controller decided to scrap the old style of language shows and introduce it so it kind of captures younger audiences, I think that was [...] key in order to get youngsters listening to [...] their mother tongue music. [...] [T] he feedback we're getting, people are liking it, people are enjoying it. And we are targeting youngsters.

(Pandya 2013, interview) 
(4) I think, from the feedback that I've had, it's seen as a positive thing, because [...] people can understand the show [...]. It's not just Gujaratis that listen to my show, and we've got a clear indication of that. [...] We have noticed through Facebook, through Twitter, through social media [that] the response that we're getting is from non-Gujaratis as well. I've got a lot of English listeners to my show. So I think we're targeting the right way.

(Pandya 2013, interview)

As Example (4) shows, the program makers clearly perceive Gujarati-English codeswitching as being part of Britain's multilingual linguistic landscape, both on air and in its digital media channels. As such, English structural elements within the show are both accepted as part of the ethnolinguistic repertoire of in-group members of the British Gujarati diaspora and designed to help along out-group listeners. For example, the bilingual show jingle (delivered by two speakers, Alpa in English and a male voice in Gujarati) presents a typical case of code-switching as exact reiteration/translation of what was said before in another language (Example 5).

(5) From Ahmedabad to Wembley, Surat to Leicester, and everywhere inbetween. The best Gujarati music, entertainment and the latest news

for you. Bringing you the best Gujarati music, entertainment and the latest news. Alpa Pandya - on BBC Asian Network.

(Underlining indicates male voice, bold font indicates translation from Gujarati.)

In the evocation of places (from Ahmedabad to Wembley, Surat to Leicester) at the beginning of the jingle, the show positions itself within the transnational community spanning from the homeland to the local diaspora, and everywhere in-between. This imagined movement between actual places is mirrored by the use of English and Gujarati, thereby establishing the two languages as symbolic spaces between which the global/local interaction takes place. Jacquemet (2010: 56) observes in the context of digital media that these "global/local interactions may also produce a new form of reterritorialization that gives rise to recombinant identities, usually produced through encounters between global and local codes of communication". The BBC minority language programs provide the platform for these encounters of codes, by giving their presenters considerable freedom for individualized language use, including language alternation patterns, as Alpa mentions in Example (6).

(6) [W]hat we were advised is, with all the new language shows, you can speak an element of English, because [...] we all know Gujaratis do not just speak Gujarati - when they're speaking to their friends, they will mix in a bit of 
English, they will mix in Gujarati, and some of them even mix in a bit of Hindi. So it's about mixture of languages and making it into one language. I think that's the key. So, [...] with my show, I was told probably 80 per cent Gujarati, 20 per cent English. Sometimes we don't stick to that. And I think [...] it depends on the kind of audience you're getting, you know what kind of listenership you're getting, so you can tweak it, and can kind of say, well okay, we'll do 30 per cent English and 70 per cent Gujarati. But Gujarati is key, there has to be a high percentage of Gujarati, because it is a Gujarati show.

(Pandya 2013, interview)

Alpa here again refers to the communicative practices of the younger Gujarati community in the UK, arguing that code-switching is a regular feature of ingroup interactions. As such, language alternation is both appropriate for and indexical of a local diasporic identity. While the BBC clearly monitors the use of the heritage language in their Asian Network programs, it also allows the presenter to project the local voice of the transnational community, thereby acting as an institutional space for contextualized socio-cultural practices and identity negotiations. This role of the radio as a platform for and multiplier of dialectal styles as well as stylization has been observed in previous research, too (cf., e.g. Bell 1984; 2001; Coupland 2001; and Blommaert 2007).

In the following, two examples show Alpa Pandya's local style of codeswitching on the BBC radio show (Examples 7-8). Bold font indicates translation from Gujarati.

(7) We are still in this great, oh-so-hot heat, I am enjoying this frying heat. I hear so many people around me who say, 'Oh, it's too hot. It's too hot. The heat is getting to me'. And I say why do you curse the heat, hey? After so many prayers, we get this kind of sunshine, so why don't you just enjoy! No doubt, the rain and cold is around the corner any time soon, so all I would say is, just enjoy it!

(Alpa Pandya Show, 21 July 2013)

(8) Many, many Gujaratis are residents of South Africa, and of course, Nelson Mandela was an important, great personality. He still is, in my eyes; so you'll get to listen to the reactions from South Africa, on this emotional and very, very sad day today. And that will be in the second hour of the show. Also on the show tonight, with a young artist who is trying to make an entry into the world of song and music, with the help of a talent show.

(Alpa Pandya Show, 8 December 2013) 
Both examples exhibit amongst others a range of the typical structural microlevel switches with regard to the discourse functions accomplished (such as reiteration, quotation, asides, and other discourse-structuring devices, see e.g. Gardner-Chloros et al. 2000). However, the focus here lies on the overall use of code-switched language in the Gujarati radio program situation. As Auer (2005: 406) proposes, this is

another quite different way of looking at code-switching as an index of social identity. This perspective considers mixing/switching itself a style which indexes different types of social membership beyond the memberships indexed by the monolingual varieties involved. Hybrid ways of speaking (not the individual acts of alternation) symbolize social identities which can be considered (by the analyst) to be equally hybrid (multiple, flexible, changing, malleable).

(Auer 2005: 406)

Thus, code-switching on the Alpa Pandya show is to be seen as a stylistic choice that indexes an awareness of hybrid social affiliations. By virtue of it being mediated language, this code-switched variety also acquires notions of increased importance and continuity. As maintained by Bell (1984: 192), “[m] edia style has to carry the continued weight of declaring an ingroup identity. It must therefore be sustained, not temporary. It becomes institutionalized and hence largely predictable". This sustained link between a linguistic style and its social meanings is captured by the term enregisterment, defined as the result of "processes whereby distinct forms of speech come to be socially recognized (or enregistered) as indexical of speaker attributes by a population of language users" (Agha 2005: 38).

In the case of Gujarati-English code-switching, attributes and indexicalities can be observed at the hand of meta-linguistic commentary on language use in the show. Examples (9) and (10) characterize the use of both languages as positive (Example 9), and provide a light-hearted label for the code-switched variety (Example 10). The use of Gujarati is again indicated by bold font.

(9) Where we give you the best of both languages - the Gujarati and English. (Alpa Pandya Show, 23 June 2013)

(10) English and Gujarati ... of course we call it Guj-lish on the show. (Alpa Pandya Show, 7 April 2013)

Finally, and similar to the morphological blending (Guj-lish) of the language terms observed in Example (10), Alpa uses the hyphenated term Brit-Gujarati to refer to the hybrid character of the show with regard to language use (Example 11; cf. also Example 1). 
(11) It's the only Brit-Gujarati show of its kind. No other radio station does it quite the way we do it here on the BBC Asia Network, of course on the Alpa Pandya show. So be proud of it, is what I'll say.

(Alpa Pandya Show, 7 April 2013)

Studies on ethnic identity find that second-generation immigrants in particular adopt transnational identities (e.g. Mukadam and Mawani 2007; Somerville 2008), suggesting predominantly acculturative ethnic identification patterns and preference of hybrid or hyphenated terminology in self-definition. The application of a hyphenated term to the radio program thus clearly constructs it as a liminal space for diasporic identity negotiations.

\section{Conclusion}

This article explores linguistic identity construction and language attitudes of radio show host Alpa Pandya. Treating her as an exemplary member of the younger British Gujarati community, her use of Gujarati-English code-switching is both seen as indicative of in-group language use as well as influential in creating contextualized socio-cultural practices and negotiating local, hybrid identity construction. The BBC Asian Network represents a platform on which radio hosts can use their linguistic resources relatively freely to engage with and shape the communicative practices of younger-generation diasporic Asians in the UK. The emerging picture of British Gujarati identity resonates with the history of transnational migration, global connectedness and local contextualizations. The act of switching between linguistic codes can thus be conceptualized as movement between symbolic or virtual spaces, between the "here and there" combined in the migrant speaker. However, Auer (2005: 403) "warns of a rash equation of 'hybrid' language use with 'hybrid' social identity", urging the researcher to consider specific circumstances and constellations before claiming indexical links between the linguistic and the social. This is particularly true for secondor third-generation migrants, for whom the relationship between the "here and there" is certainly not only different than it is for first-generation migrants, but also differently weighted and informed. Rather than equating hybrid language use with hybrid identities (if there is such a thing as the latter), I hope to have highlighted the fact that reports of language attitudes and ethnic identity construction can be connected to localized communicative practices in an attempt to define their indexicality and enregisterment.

With regard to the possibility of establishing indexical links between observed linguistic behavior and the social identity of British Gujarati speakers, 
an investigation of more data in an in-depth study of code-switching would be needed, as would a larger-scale perception study to establish enregisterment, acceptance and status of a code-switched local variety within and outside the community.

Acknowledgements: I am indebted to Alpa Pandya for agreeing to this study based on an introduction through a colleague, to the editors of this volume for their support and guidance, to my reviewers for helpful suggestions and constructive criticism and to the commercial translating service for speedy and reliable work. All faults remain my own.

\section{References}

Agha, Asif. 2005. Voice, footing, enregisterment. Journal of Linguistic Anthropology 15(1). 38-59.

Alam, Farhana \& Jane Stuart-Smith. 2011. Identity and ethnicity in /t/in Glasgow-Pakistani highschool girls. In Wai-Sum Lee \& Eric Zee (eds.), Proceedings of the 17th International Congress of Phonetic Sciences, 17-21 August 2011, Hong Kong. Hong Kong: Department of Chinese, Translation and Linguistics, City University of Hong Kong, 216-219. < https://www.internationalphoneticassociation.org/icphs-proceedings/ICPhS2011/ OnlineProceedings/RegularSession/Alam/Alam.pdf > (accessed 29 June 2017).

Alpa Pandya show. <http://www.bbc.co.uk/programmes/b01p470d > (accessed 24 February 2015).

Auer, Peter. 1999. From codeswitching via language mixing to fused lects toward a dynamic typology of bilingual speech. International Journal of Bilingualism 3(4). 309-332.

Auer, Peter (ed.) 2002. Code-Switching in conversation: Language, interaction and identity. London \& New York: Routledge.

Auer, Peter. 2005. A postscript: Code-switching and social identity. Journal of Pragmatics 37(3). 403-410.

BBC Asian Network. Policy. < http://www.bbc.co.uk/aboutthebbc/insidethebbc/howwework/ accountability/statements2010/radio/asian > (accessed 18 February 2015).

Bell, Allan. 1984. Language style as audience design. Language in Society 13(2). 145-204.

Bell, Allan. 2001. Back in style: Reworking audience design. In Penelope Eckert \& John R. Rickford (eds.), Style and sociolinguistic variation, 139-169. Cambridge: Cambridge University Press.

Bhatt, Rakesh M. 2008. In other words: Language mixing, identity representations, and third space. Journal of Sociolinguistics 12(2). 177-200.

Blommaert, Jan. 2007. Sociolinguistics and discourse analysis: Orders of indexicality and polycentricity. Journal of Multicultural Discourses 2(2). 115-130.

Blommaert, Jan. 2015. Commentary: Superdiversity old and new. Language \& Communication 44. 82-88.

Blommaert, Jan \& Ben Rampton. 2011. Language and superdiversity. Diversities 13(2). 3-23.

Brettell, Caroline B. 2006. Introduction: Global spaces/local places: Transnationalism, diaspora, and the meaning of home. Identities: Global Studies in Culture and Power 13(3). 327-334. 
Browne, Donald R. \& Enrique Uribe-Jongbloed. 2013. Introduction: Ethnic/linguistic minority media - What their history reveals, how scholars have studied them and what we might ask next. In Elin Haf Gruffydd Jones \& Enrique Uribe-Jongbloed (eds.), Social media and minority languages: Convergence and the creative industries, 1-28. Bristol: Multilingual Matters.

Brubaker, Rogers. 2005. The 'diaspora' diaspora. Ethnic and Racial Studies 28(1). 1-19.

Cheshire, Jenny, Paul Kerswill, Sue Fox \& Eivind Torgersen. 2011. Contact, the feature pool and the speech community: The emergence of Multicultural London English. Journal of Sociolinguistics 15(2). 151-196.

Cormack, Mike. 2005. The cultural politics of minority language media. International Journal of Media and Cultural Politics 1(1). 107-122.

Coupland, Nikolas. 2001. Dialect stylization in radio talk. Language in Society 30(3). 345-375.

Coupland, Nikolas. 2010. The authentic speaker and the speech community. In Carmen Llamas \& Dominic Watt (eds.), Language and identities, 99-112. Edinburgh: Edinburgh University Press.

Day, Julia. 2006. Asian Network gets booster signal. The Guardian. < http://www.theguardian. com/media/2006/jan/26/bbc.digitaltv > (accessed 24 October 2015).

Evans, Bronwen, Ajay Mistry \& Caroline Moreiras. 2007. An acoustic study of first- and secondgeneration Gujerati immigrants in Wembley: Evidence for accent convergence? In Jürgen Trouvain \& William John Barry (eds.), Proceedings of the 16th International Congress of Phonetic Sciences, Saarbrücken, 6-10 August 2007, Dudweiler: Pirrot GmbH, 1741-1744. < http://www.icphs2007.de/conference/Papers/1505/1505.pdf> (accessed 24 February 2015).

Gardner-Chloros, Penelope, Reeva Charles \& Jenny Cheshire. 2000. Parallel patterns? A comparison of monolingual speech and bilingual codeswitching discourse. Journal of Pragmatics 32(9). 1305-1341.

Gumperz, John J. 1982. Discourse strategies. Cambridge: Cambridge University Press.

Hall, Stuart. 1991. Old and new identities, old and new ethnicities. In Anthony D. King (ed.), Culture, globalization and the world-system, 41-68. Houndsmills: Macmillan.

Isajiw, Wsevolod W. 1975. The process of maintenance of ethnic identity: The Canadian context. In Paul Migus (ed.), Sounds Canadian: Languages and cultures in multiethnic society, 129138. Toronto: Peter Martin Associates.

Jacquemet, Marco. 2010. Language and transnational spaces. In Peter Auer \& Jürgen Erich Schmidt (eds.), Language and space: An international handbook of linguistic variation. Volume 1: Theories and methods, 50-69. Berlin \& New York: Walter de Gruyter.

Karim, Karim Haiderali. 2003. Mapping diasporic mediascapes. In Karim Haiderali Karim (ed.), The media of diaspora, 1-18. London New York: Routledge.

Lawson, Sarah \& Itesh Sachdev. 2004. Identity, language use, and attitudes: Some SylhetiBangladeshi data from London, UK. Journal of Language and Social Psychology 23(1). 49-69.

Mattausch, John. 2007. A chance diaspora: British Gujarati Hindus. In Gijsbert Oonk (ed.), Global Indian diasporas: Exploring trajectories of migration and theory, 149-166. Amsterdam: International Institute for Asian Studies/Amsterdam University Press.

Mukadam, Anjoom Amir \& Sharmina Mawani. 2007. Diaspora revisited: Second-generation Nizari Ismaili Muslims of Gujarati ancestry. In Gijsbert Oonk (ed), Global Indian diasporas: Exploring trajectories of migration and theory, 195-209. Amsterdam: International Institute for Asian Studies/Amsterdam University Press.

Muysken, Pieter. 2000. Bilingual speech: A typology of code-mixing. Cambridge: Cambridge University Press. 
Myers-Scotton, Carol. 1993. Common and uncommon ground: Social and structural factors in codeswitching. Language in Society 22(4). 475-503.

Oonk, Gijsbert. 2006. South Asians in East Africa (1880-1920) with a particular focus on Zanzibar: Toward a historical explanation of economic success of a middlemen minority. African and Asian Studies 5. 57-89.

Oonk, Gijsbert (ed.) 2007. Global Indian diasporas: Exploring trajectories of migration and theory. Amsterdam: International Institute for Asian Studies/Amsterdam University Press.

Pandya, Alpa. 2013. Interview conducted by Lena Zipp on September 4th, 2013, in Leicester, UK.

Poplack, Shana. 1980. Sometimes l'll start a sentence in Spanish y termino en Español: Toward a typology of code-switching. Linguistics 18(7-8). 581-618.

Poplack, Shana. 1988. Contrasting patterns of code-switching in two communities. In Monica Heller (ed.), Codeswitching: Anthropological and sociolinguistic perspectives, 215-244. Berlin \& New York: Mouton de Gruyter.

Poros, Maritsa V. 2011. Modern migrations: Gujarati Indian networks in New York and London. Stanford, CA: Stanford University Press.

Ramji, Hasmita. 2006a. Journeys of difference: The use of migratory narratives among British Hindu Gujaratis. Ethnic and Racial Studies 29(4). 702-724.

Ramji, Hasmita. 2006b. British Indians 'returning home': An exploration of transnational belongings. Sociology 40(4). 645-662.

Rathore, Claudia. 2013. Dialect variation and change in the diaspora. A sociophonetic study of the East African Indian community in Leicester, UK. Zurich: University of Zurich dissertation.

Robinson, Vaughan. 1993. Marching into the middle classes? The long-term resettlement of East African Asians in the UK. Journal of Refugee Studies 6. 230-247.

Sahoo, Ajaya Kumar. 2006. Issues of identity in the Indian diaspora: A transnational perspective. Perspectives on Global Development and Technology 5(1-2). 81-98.

Sharma, Devyani. 2011. Style repertoire and social change in British Asian English. Journal of Sociolinguistics 15(4). 464-492.

Sharma, Devyani. 2012. Stylistic activation in ethnolinguistic repertoires. University of Pennsylvania Working Papers in Linguistics 18(2). 127-136.

Sharma, Devyani \& Ben Rampton. 2015. Lectal focusing in interaction: A new methodology for the study of style variation. Journal of English Linguistics 43(1). 3-35.

Sharma, Devyani \& Lavanya Sankaran. 2011. Cognitive and social forces in dialect shift: Gradual change in London Asian speech. Language Variation and Change 23(3). 399-428.

Somerville, Kara. 2008. Transnational belonging among second generation youth: Identity in a globalized world. Journal of Social Sciences 10(1). 23-33.

Van Hear, Nicholas. 1998. New diasporas. The mass exodus, dispersal and regrouping of migrant communities. London: UCL Press.

Vertovec, Steven. 1999. Conceiving and researching transnationalism. Ethnic and Racial Studies 22(2). 447-462.

Vertovec, Steven. 2007. Super-diversity and its implications. Ethnic and Racial Studies 30(6). 1024-1054. 